\title{
Collective Apathy and Racial Health Disparities in the USA: the Need for Empathy-Building and Examples of Positive Change
}

\author{
James M. DuBois, DSc, PhD (1) \\ Bioethics Research Center, Department of Medicine, Washington University School of Medicine, St. Louis, MO, USA.
}

$\mathrm{J}$ Gen Intern Med 36(7):2123-4

DOI: $10.1007 / \mathrm{s} 11606-021-06673-0$

() Society of General Internal Medicine 2021

I n 1906, W.E.B. DuBois wrote that the health disparities between Blacks and Whites in the USA are largely matters of condition - sanitation, education, and economics - rather than racial traits and tendencies. ${ }^{1}$ He wrote this to challenge the explicitly racist view that Black people were dying at higher rates than Whites because they are inferior. The particular causes of death that concerned W.E.B. DuBois have changed, but significant disparities persist. Moreover, a subtle form of racism persists that sustains the conditions that give rise to health disparities.

In the wake of recent killings of unarmed Black people by police, books such as White Fragility by Robin Diangelo and How to be an Anti-racist by Ibram Kendi have appeared on bestseller lists. These books remind us that systemic racism often lacks the intentional prejudice associated with individual racism; however, it is insidious as it sustains inequities that benefit empowered majority groups. Consider the following disparities in health outcomes and spending:

- Black women's maternal mortality is three times that of White women ${ }^{2}$

- Black people are 2-3 times more likely than White people to die of preventable strokes or heart disease ${ }^{3}$

- Cystic fibrosis, which affects primarily White people, receives 11 times more government funding and 440 times more foundation funding than sickle cell disease, which predominantly affects Black people. This is the case even though three times as many people suffer from sickle cell disease than cystic fibrosis. ${ }^{2}$

Wheeler and Bryant dissect the diverse causes of racial and ethnic health disparities in the USA. ${ }^{4}$ They observe effects at the level of provider behaviors, patients, and systems. ${ }^{4}$ Racism - systemic or otherwise — cannot be assumed to be

Received August 7, 2020

Accepted February 16, 2021

Published online March 2, 2021 the root cause of every disparity, but it clearly plays a role in some disparities. To return to one example provided above, consider this question: If in 2021, White women started dying in childbirth at rates three times as high as Black women, what would happen?

This question gets at the heart of the matter: US society would take action, because the lives affected matter to the majority of people who live in the USA, and crucially, to those with financial means. Martin Luther King Jr. stated that the greatest tragedy in the pursuit of social justice is "not the strident clamor of the bad people, but the appalling silence of the good people...," which he characterized as apathy. ${ }^{5}, \mathrm{p}$. ${ }^{475}$ Whereas systemic racism in health care was once based on explicitly racist doctrines, today it often takes a much more subtle form: collective apathy. There is a kind of apathy that is not blameworthy, for example, the kind that arises from dysthymia. There is another kind that is captured in phrases such as "You just don't care about me!" or "You don't give a damn!"- accusations that apathy is a character flaw, a failure to care adequately about people or issues that matter. There are at least two sources of this latter kind of apathy.

Apathy can arise from the perception that a person or issue is not important or is less important than others. When it comes to race, we may have some intrinsic liabilities: ${ }^{6}$ Even from a very young age, we naturally feel less empathy for people who we view as different from ourselves. Additionally, our empathy for others is decreased when they are invisible to us or we lack details about their lives. Finally, our empathy for others decreases when we perceive others as a threat, and data on implicit bias indicate that many view Black people as more threatening that White people.

To address these liabilities, we might leverage increasingly popular narrative medicine activities: reflective writing on experiences with patients and discussing true stories from patients or providers on racism or disparities in healthcare. Such educational approaches have been demonstrated to increase perspective-taking and empathy among learners. Excellent teaching materials and models for sessions can be found in journals such as Academic Medicine, Health Affairs (the Narrative Matters series), and Narrative Inquiry in Bioethics. These stories may raise awareness of the suffering caused by racial health disparities, of the social determinants of health (e.g., food insecurity, financial stress, and gun 
violence), and of the many ways that individual providers, institutions, payers, and policies can fail patients. However, such sessions may do more harm than good if they are not accompanied by other institutional endeavors.

The specific risk of raising awareness and fostering empathy in the absence of action is that apathy may also arise when we feel that a worthwhile goal is not achievable. The fact that shocking health disparities between Blacks and Whites persist 64 years after the first Civil Rights Act was passed is demoralizing. Those who engage in narrative education about racial health disparities may feel overwhelmed by the enormity of the challenge, especially when so many problems arise at the level of systems, which are slow and difficult to change.

Fighting the tendency toward cynicism and discouragement is essential to fostering prosocial behavior both in private life and professional life. Gibbs, a leading moral psychologist, has identified "assuming the worst" as a cognitive distortion that contributes to unethical behavior, and cynicism is correlated with worse professional decision-making and weaker endorsement of professional norms. ${ }^{7}$ We cannot just raise awareness of racial health disparities, nor even increase empathy for those who suffer from such disparities. We need to demonstrate and celebrate that progress is possible.

We can demonstrate progress by doing something rather than nothing. We can ask ourselves: Given our talents, resources, and connections, what can we do to improve the health of underserved racial groups? The popular SMART goal-setting framework is particularly relevant here: We need to set goals that are specific, measurable, achievable, realistic, and timely. In the short term, and especially at the local level, I feel that we most need to emphasize "achievable" and "measurable." The key is to demonstrate some success.

Additionally, as individuals and institutions we can study and celebrate larger models that work. We can learn about creative programs that improved outcomes for underserved racial groups on the websites of the Agency for Healthcare Quality and Research and Center for Disease Control and Prevention. These activities may stimulate the imagination as part of the goal-setting process.

Finally, we can adopt a mindset of waiting to say yes. From the beginning of the civil rights movement, Black leaders have taken different stances on the degree to which White people should lead efforts to remedy racism and disparities. One thing is certain: predominantly White institutions and White individuals need to be prepared to help when asked. This may serve as an ongoing assessment of our progress in combatting the problem.

If indeed today's systemic racism manifests, in part, as collective apathy in the face of disparities, then we need to maintain awareness of the problem, foster empathy for those who suffer, and constantly seek solutions. We cannot take action only when our cities face riots and protests. The specific actions that we need to take will differ radically based on our skills, resources, and ties to communities; but taking some form of action is the most promising remedy for the collective apathy that has sustained racial inequities described by W.E.B. DuBois more than 114 years ago.

Acknowledgements: The writing of this paper was supported by the S.J. Bander Professorship for Medical Ethics and Professionalism at Washington University School of Medicine.

Corresponding Author: James M. DuBois, DSc, PhD; Bioethics Research Center, Department of Medicine, Washington University School of Medicine, St. Louis, MO, USA (e-mail: duboisjm@wustl.edu).

\section{REFERENCES}

1. DuBois WEB. The health and physique of the Negro American. Am J Public Health. 1906/2003;93(2):272-276.

2. Carroll AE. Health disparities among Black persons in the US and addressing racism in the health care system. In. JAMA Health Forum;2020.

3. Ferdinand KC, Yadav $\mathbf{K}$, Nasser SA, et al. Disparities in hypertension and cardiovascular disease in blacks: the critical role of medication adherence. J Clin Hypertens. 2017;19(10):1015-1024.

4. Wheeler SM, Bryant AS. Racial and ethnic disparities in health and health care. Obstet Gynecol Clin N Am. 2017;44(1):1-11.

5. King ML Jr. Stride toward freedom. In: Washington JM, ed. A testament of Hope: the Essential Writings and Speeches of Martin Luther King, Jr. San Francisco: Harper Collins; 1958 / 1986:417-490.

6. Stevens L, Woodruff CC, eds. The Neuroscience of Empathy, Compassion and Self-compassion. San Diego: Elsevier; 2018.

7. DuBois JM, Chibnall JT, Gibbs JC. Compliance disengagement in research: development and validation of a new measure. Sci Eng Ethics. 2015;22(4):965.

Publisher's Note: Springer Nature remains neutral with regard to jurisdictional claims in published maps and institutional affiliations. 